ANA MOYER

Sea of the Universe:

Sculptural Self-Portraits of

Mari Katayama 


\section{ANA MOYER \\ Sea of the Universe: Sculptural Self-Portraits of Mari Katayama}

Mari Katayama is a Japanese contemporary multi-media artist born in 1987, working primarily in photography, sculpture, textile, and self-portraiture as provocation. Katayama examines ideas of disability, femininity, and physicality through the use of prosthetics and bodily objectification. Her works comment on performative gender, Orientalist stereotypes such as the China Doll, the commodification of the disabled body through the creation of fantasy spaces, the Chthulucene, and immersive reworlding. And while her body features prominently in her images, both in intimate settings and delicate landscapes, Katayama notes, "I use my body as material simply because it's handy. I don't think it's correct to say my body is the subject or the theme of my art." Following three artwork series, bystander, you're mine, and High Heel Project, this essay will attempt to examine and contextualize key themes embodied within Mari Katayama's work, particularly with regard to disability and femininity.

Mari Katayama was born with the rare congenital disorder tibial hemimelia, wherein the tibia (shin bone) is absent. The disorder also affects her left hand. ${ }^{2}$ As a child, she was offered the choice of spending her life in a wheelchair or undergoing amputation of her lower legs in order to use prostheses. ${ }^{3}$ At the age of nine, she underwent the amputation and a lengthy recovery, eventually gaining the independence to walk. ${ }^{4}$ Growing up in Ota, Gunma prefecture, Katayama notes the influence of intercultural exchange brought in from the neighbouring town Oizumi, known as "Brazil-town," as well as the interactions she had with other disabled or sick children, as major contributors to her modes of thinking. ${ }^{5}$ Encouraged both by the women in her family and driven by a need for modified clothing, Katayama was taught to make her own clothes. "[My mother] always taught me if anything is missing, I should be responsible for making [it] by myself," she says. "I grew up in that kind of environment where the DIY mentality is treated as common sense." "She also notes that the lack of resources in Japanese social welfare systems, including that of modified clothing for disabled people, is a significantly overlooked factor. ${ }^{7}$ Utilizing new modes of 
communication available through social media, Katayama began to connect to other people by sharing photographs of objects and drawings she had made. ${ }^{8}$ In high school, she was contacted by fashion student Tatsuya Shimada, who asked her to model for his graduation show. After this, Katayama took the first of her self-portraits wearing a blonde wig and sitting behind ornate, embroidered stuffed legs. She notes, "They were the legs I lost. That was how I imagined them. Right from the beginning, I saw myself as one of the raw materials to use in my work." 9

The 2014 series you're mine examines different iterations of the body through the lens of Katayama's "selves," which are seen in contrast with each other. The first is a complete plaster cast of her body, including details such as fingerprints. The cast is covered in a hand-sewn tan leather "skin" and a mannequin wig made from her own hair. ${ }^{10}$ Most notably, the face is a small mirror surrounded by lightbulbs, reflecting our natural inclination to copy behaviours of the individuals around us. The second self is found in a large photographic self-portrait: Katayama reclines in a white bed in a pose reminiscent of Titian's Venus, wearing heavy makeup and lingerie as a reflection of her "social face." However, upon closer inspection, her stockings are in fact medical compression bands, a paradoxical object that begins to reveal a duality of identity. ${ }^{11}$ Lastly, her third self is found in a full-length mirror, which she notes is her "current self." Certainly, the artist emphasizes a sexuality and eroticism in both the materials and poses that she uses, particularly in the photograph. Examining the transhuman object, Katayama deconstructs

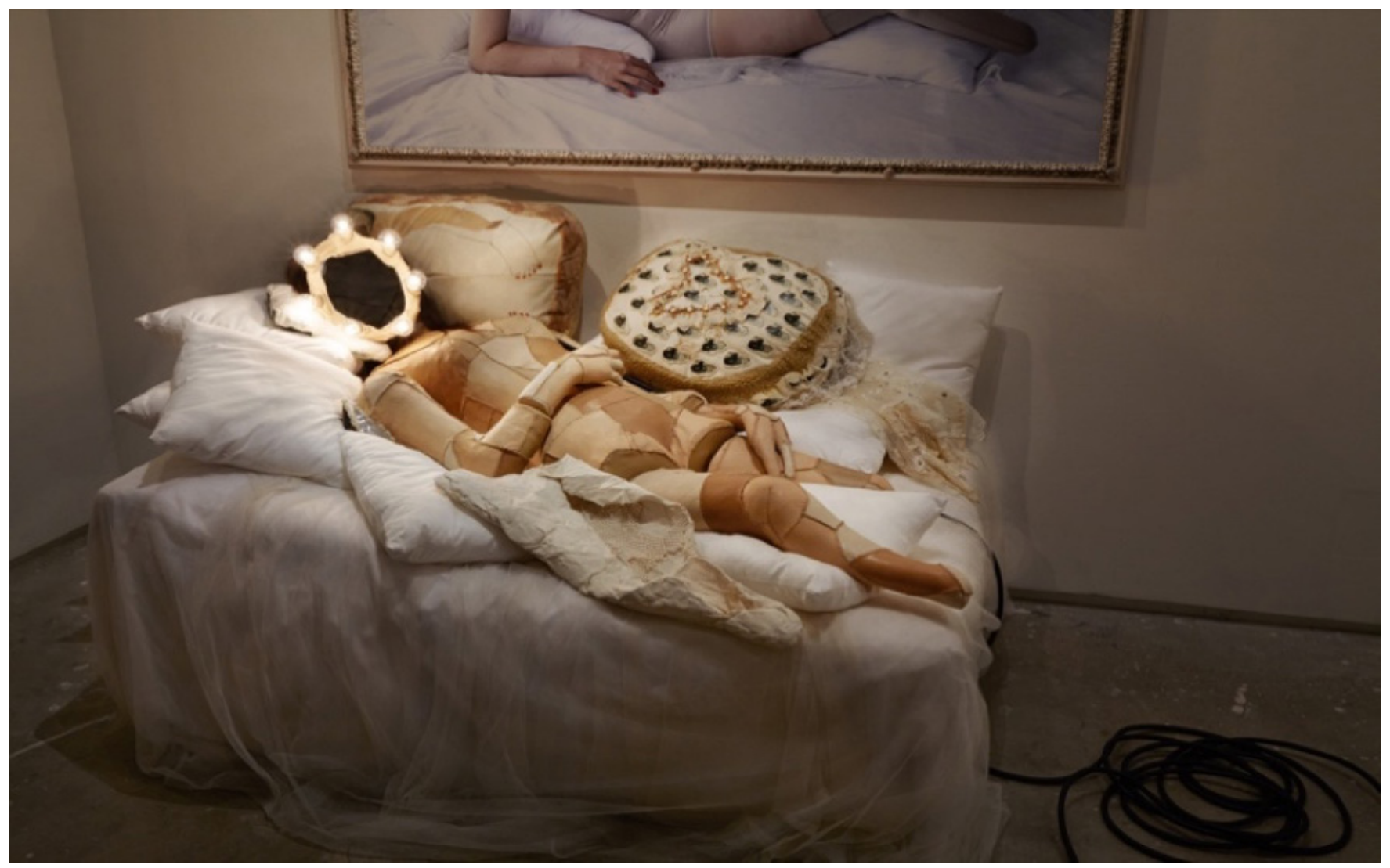

Mari Katayama, you're mine \#000, 2014, leather, plaster, hair, mirror and lights. In Traumaris exhibition space. 


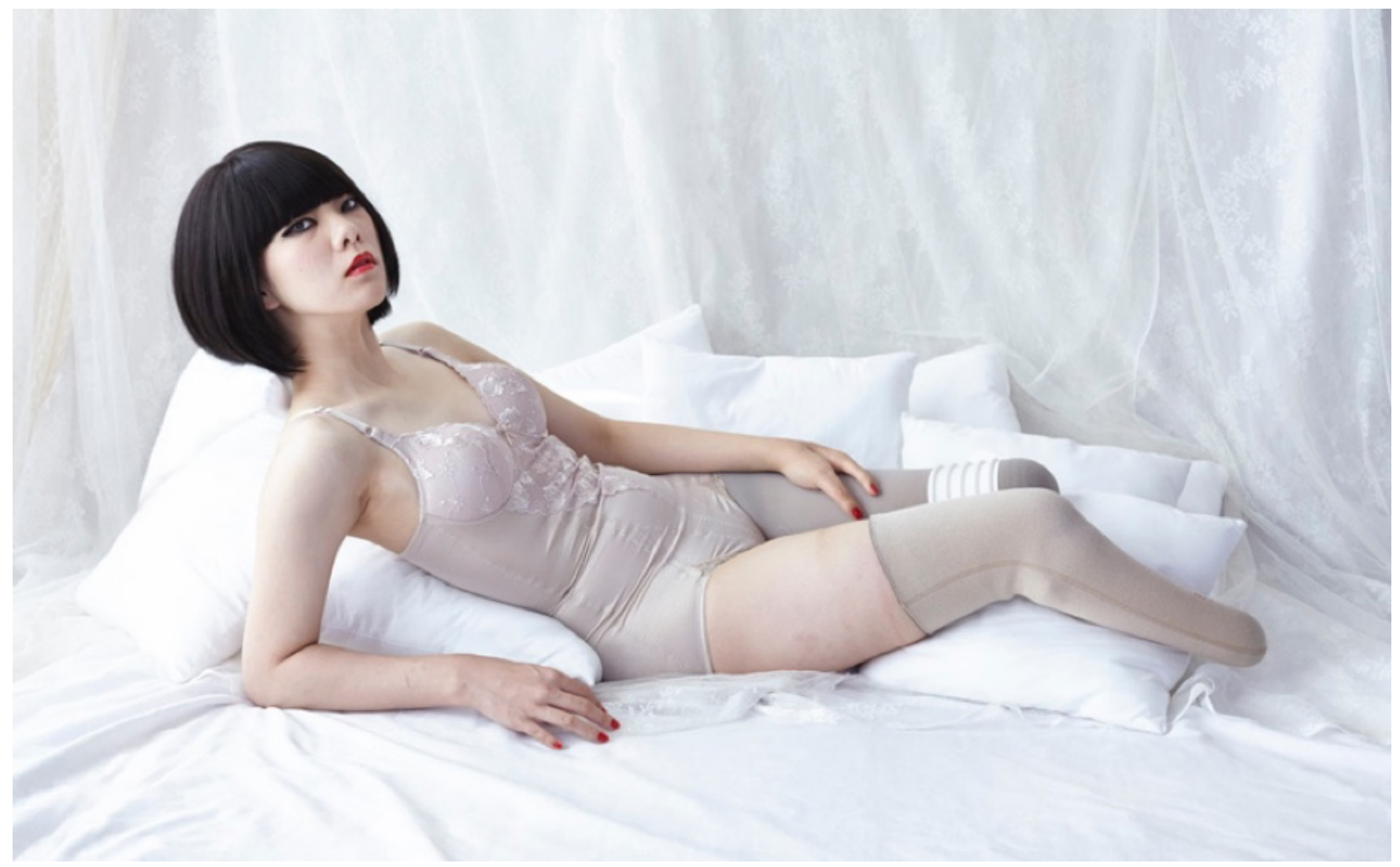

Mari Katayama, you're mine \#001, 2014, Lambda print (credit: Mari Katayama).

aesthetic ideals through theatrical arrangements of form and femininity. ${ }^{12}$ As Grzegorz Kubinski notes, the compression bands become a liminal or transitional object that can be differentiated through Michel Foucault's concept of disability versus monstrosity. ${ }^{13}$ Katayama adheres to strict feminine beauty ideals while paradoxically existing outside of the accepted realm of said standards. Within disability advocacy, online spaces have grown wherein women with disabilities can express their identity and sexuality. However, many of these online spaces remove the nuance of identity, with the individual integrating their "defect" as a key element of their personality and outward identity. ${ }^{14}$ By simultaneously embracing elements of the grotesque and alluring, including subtle ambivalences such as the medical accessories alongside lingerie, Katayama remains ambiguous about her own identity. Rather than castigating or glorifying her disability, she simply accepts it as reality and asks the viewer to do the same. ${ }^{15}$

The 2016 bystander series has drawn significant public attention and is likely her most popular body of work. While commuting to the Setouchi region from Gunma, Katayama noticed that her physical limitations often meant she needed helpers to "give a hand." 16 her creative process was also inspired by a particular form of traditional all-female Japanese puppet theatre called Naoshima Onna Bunraku. " "The dolls for bunraku don't have legs," she says. "They use elbows and hand movements to express themselves instead. It made me think how versatile hands are."18 The bystander series heavily features sea motifs, including one photo series at Naoshima Island, wherein Katayama reclines on the beach surrounded by embroidered lower appendages and pillows. ${ }^{19}$ Furthermore, the limbs include printed images of the hands 


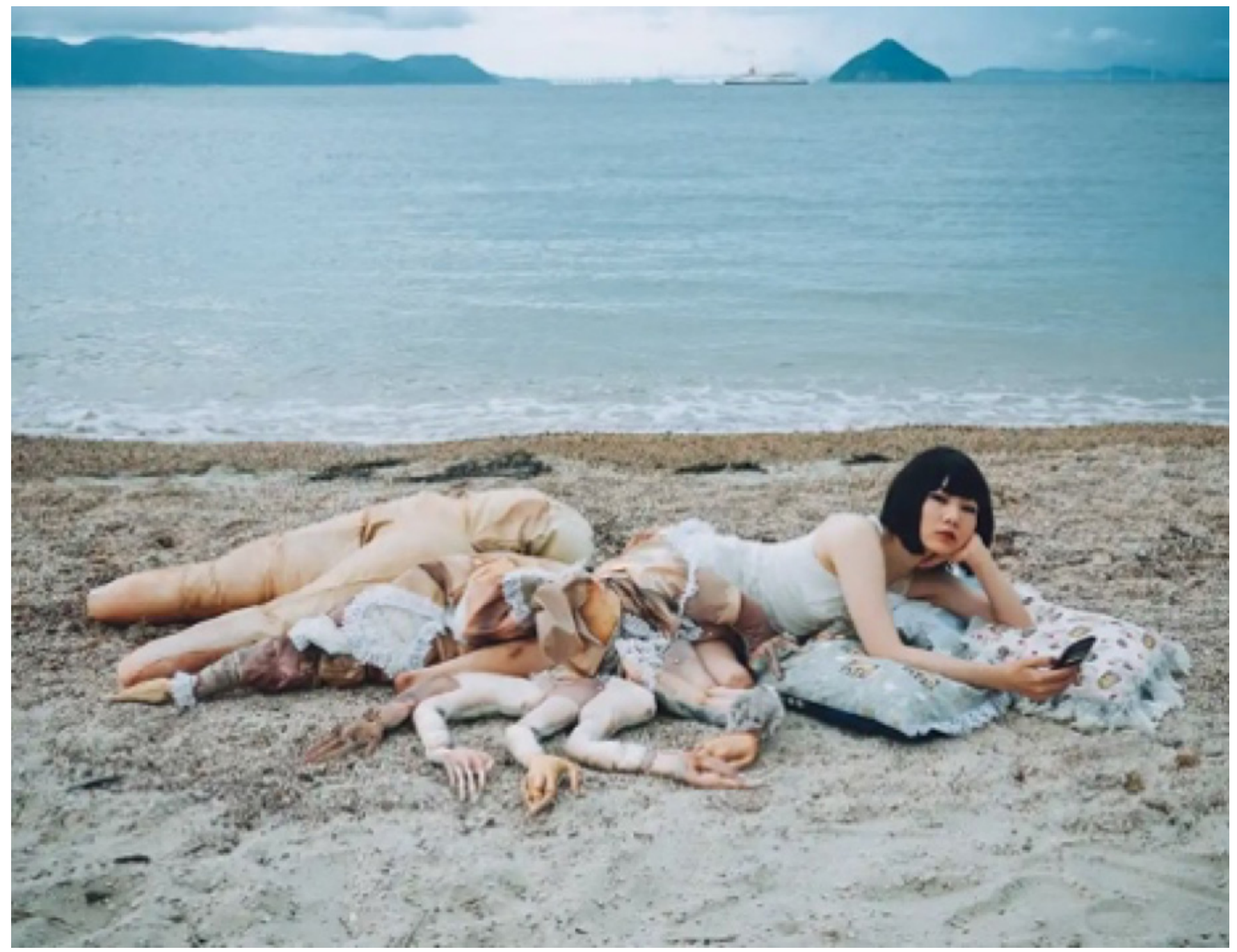

Mari Katayama, bystander \#016, 2016, Lambda print (credit: Mari Katayama).

of Japanese puppeteers, perhaps reflecting the importance of community support for individual success. The hand-sewn body replicates Katayama's unique physique - truncated legs and split left hand - and is decorated with lace, shells, pearls, and Swarovski crystals. Conceiving her body as a living sculpture, Katayama tackles themes of identity and conformity, as well as supernatural fantasy spaces that navigate new interpretations of the disabled body. Her cleft hand, which she often likens to a crab's pincers, has been a source of inspiration for the heavy sea themes found within her work. ${ }^{20}$ However, Kubinski notes the deep associations her works have with the Japanese ukiyo-e art practice, particularly the shunga genre ("spring pictures"), which embraces erotic imagery. ${ }^{21}$

Katsushika Hokusai's work The Dream of the Fisherman's Wife depicts the embodiment of pleasure and sensuality, re-writing boundaries of sexual pleasure and female masturbation. ${ }^{22}$ The work is both disturbing and erotic - the originator of tentacle porn genres-and is deeply tied to taboo sexual acts through the metaphor of the octopus. As Donna Haraway notes, "tentacle comes from the Latin tentaculum, meaning 'feeler', and tentare, meaning 'to feel' and 'to try'; [...] the tentacular ones make attachments 


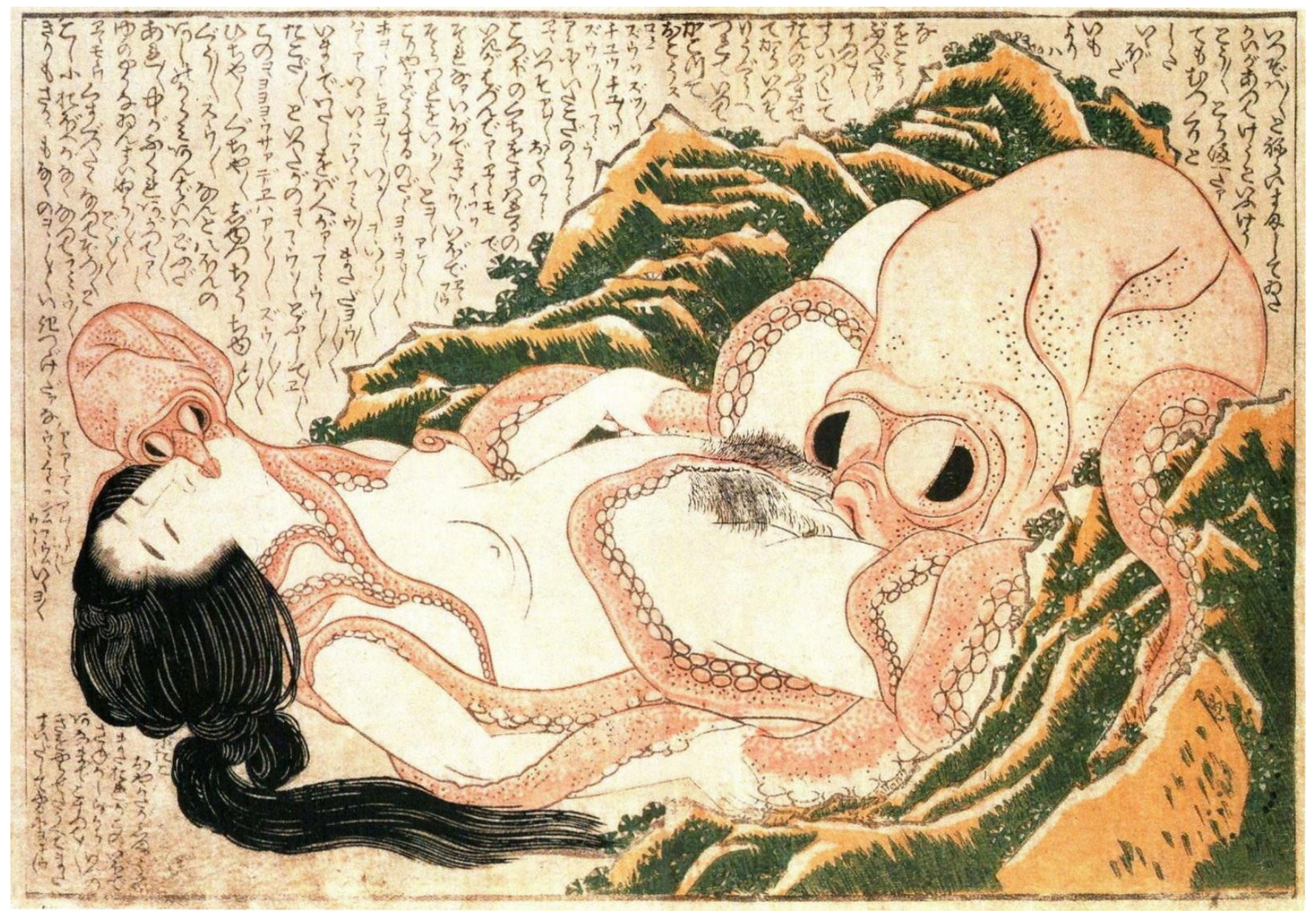

Katsushika Hokusai, The Dream of the Fisherman's Wife, 1814, woodblock print (credit: Artsy.net).

and detachments; they are both open and knotted in some ways and not others." ${ }^{23}$ Katayama's work ties into the motifs found within the Chthulucene, wherein water lies within the material level but is never neutral through specific assemblages. Within this realm, tentacular thinking rejects binary thinking, instead synthesizing both bodily practices and networks as composed of string-like patterning, thereby creating a collective entanglement. ${ }^{24}$ Thus it entangles the Human and Non-Human, creating new modes of kinship. Her own assemblage of limbs, tentacular-like tendrils ending with hands, creates inhuman supernatural fantasies of body and function. Furthermore, it relates to Astrid Neimanis' work on figuring bodies of water, of posthuman gestationality. ${ }^{25}$ Neimanis notes, "This gestationality challenges the primacy of human heteronormative reprosexuality as the cornerstone for proliferating life, yet without washing away a feminist commitment to thinking the difference of maternal, feminine, and otherwise gendered and sexed bodies." ${ }^{26}$ Katayama's acknowledgement of entanglements, through tentacles and an assemblage of puppeteer's hands, invoke ideas around community, disability, and the intersections of femininity. Much like cephalopods, her artworks come in many visual forms and abstractions, both delicate and resilient.

Katayama's works refer to ambiguous liminal spaces, a theme found elsewhere in Japanese manga, such as Daisuke Igarashi's Children of the Sea. Chapter 8, The Realm of the Sea, explores the occurrence of children raised by sea mammals-feral children-who begin to wash ashore, dead with healed bodily muti- 
lations. ${ }^{27}$ Her work similarly explores the baroque grotesque of imperfect corporeality through liminal spaces, particularly the beach - a place of birth and burial. It creates a paradox of sexual femininity and biologism, while simultaneously rejecting (hetero)normative bodies. Furthermore, themes of humanity are explored through her treatment of the body as an inanimate object, such as a doll or puppet. Kubiński argues, "In the Japanese tradition, a doll is not just a toy because it functions in the space of culture permeated with animism, it functions as a mediator between the worlds of what is real and fictitious, animated and inanimate."28 Just as with you're mine, Katayama's pose and use of the body is reminiscent of mannequins or dolls for sale, fulfilling patriarchal values of beauty for consumption. ${ }^{29}$ The body-doll object resides between desire and rejection, intimacy and manufactured consumption, creating another level of liminality within the surface of the body itself. ${ }^{30}$ Elements of consumerism, however, are perhaps best reflected in Katayama's earlier series: High Heel Project.

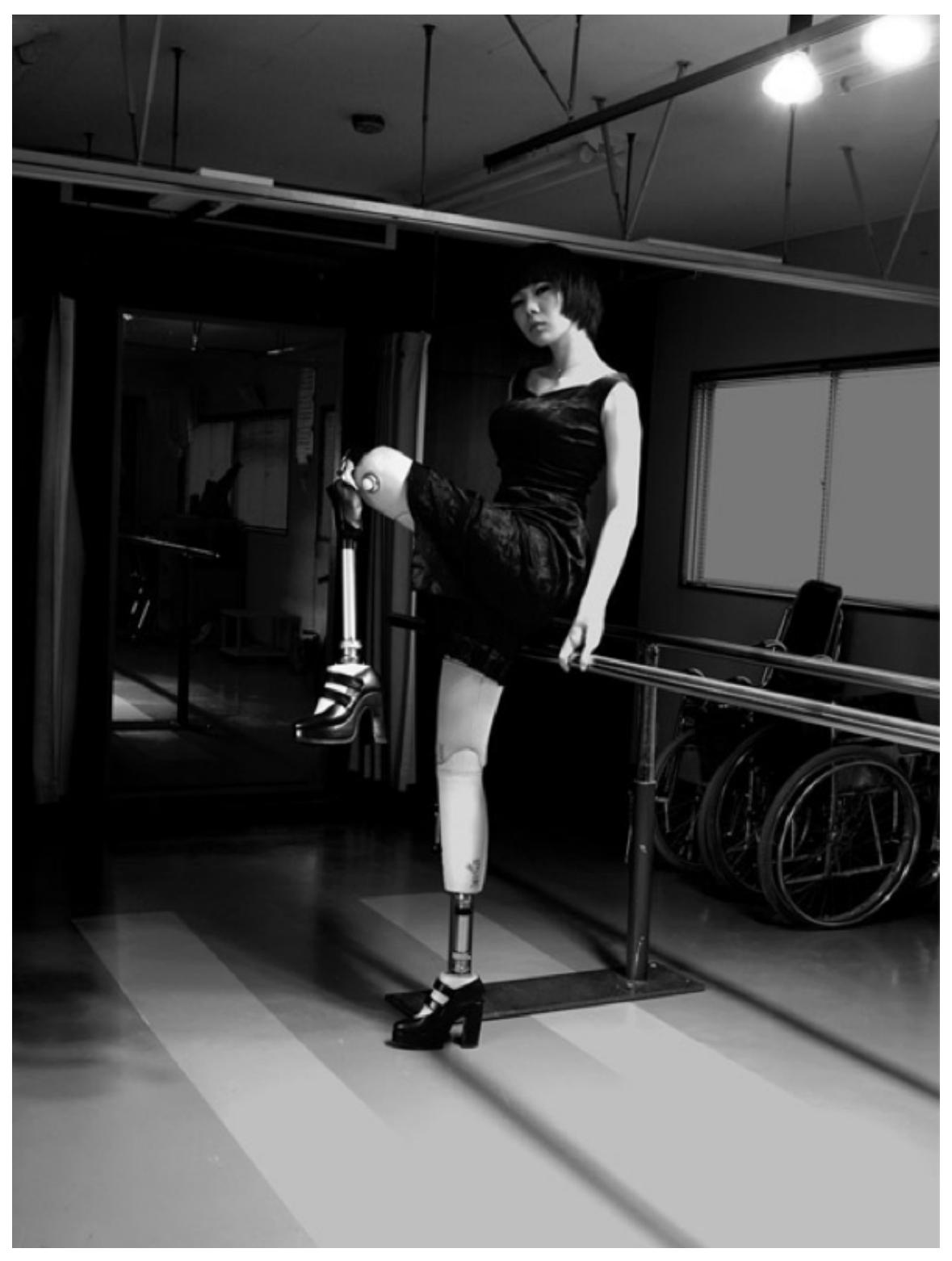

Mari Katayama, highheels, 2012, Lambda print (credit: Mari Katayama). 
The 2011 project began when the artist was a graduate student, working as a jazz singer at a bar. Katayama says, "One night, a drunk customer harassed me saying 'a woman is no longer a woman when not wearing high-heels.' I was so sad and rushed into the prosthetic limb works and that's how I started creating high-heels that are wearable with my artificial legs." ${ }^{31}$ She denotes any activity of daily life performed while wearing the high heels as part of the project. The high heel is certainly a classic symbol of femininity in twenty-first century culture, and her inability to wear normal high heels reflected cultural views of disability, "othering" the body and the individual from normal life. Furthermore, many disabled people face difficulties finding clothing that is functional, let alone aesthetically pleasing. As with any kind of accessibility modification, disabled people often face steep prices for tailored clothing and are forced to make do with home-made solutions. ${ }^{32}$ The pressure on women to perform gender is also solidified through this project. Quoting Simone de Beauvoir, Judith Butler notes, "one is not born, but, rather, becomes a woman," constituting an identity through the stylization of the body in creating an illusion of a gendered self, which is formulated through social temporality. ${ }^{33}$ Katayama's work thus comments on gender expression through highly stylized femininity, which the disabled body is often distanced from through the imposed asexualization of disabled peoples. High Heel Project also harkens back to Katayama's modeling experience in high school. Originally, designer Shimada asked her to draw fairies on her prosthetic legs to accentuate the Harajuku fashion his pieces referenced, but instead she drew thistles. ${ }^{34}$ These limbs were immortalized in one of her early works in tandem with the High Heel Project, my legs. Versions of the "artistic" prosthesis create visions of a new type of accessory or fashion object, blurring corporeal boundaries, performed gender, and commodity fetishism. ${ }^{35}$

Singer and model Viktoria Modesta released the single Prototype in $2014 .^{36}$ The music video fictionalizes narratives from her life, such as an injury to her leg at birth which eventually led to amputation at age 20. ${ }^{37}$ The video blends disability with superhuman abilities, with Modesta even using her prosthetic leg as a weapon of sorts in one scene. Throughout the video, as well as her modelling career, she has an array of designer prosthetics with matching outfits. Perhaps her most iconic look is the large black spike prosthesis which she refers to as, "a giant stiletto heel," merging body and prostheses into new forms of cyborg fashion embodiments and networks of subjecthood. ${ }^{38}$ With regard to the body's relation to consumer culture comes the idea of disability aesthetics: "a different kind of gaze predicated not on imposing normalcy but on exploring alternative modes of embodiment; one that allows us 'to elaborate disability as an aesthetic value in itself." "39 Through disability aesthetics, amputees are established as consumers, disabled bodies and de-medicalized and incorporated into capitalist culture. ${ }^{40}$ Katayama realized this discrepancy, noting that the Japanese welfare and healthcare systems directly inhibited disabled individuals from participating in consumer culture such as fashion. ${ }^{41}$ But while Modesta remains firmly within the aesthetics and consumerism of the fashion world, particularly as a model, Katayama reaches further through her use of what has been termed "DIY ethic." Modesta remains entrenched within the world of high fashion, while Katayama comments on the expectation of performing gender in personal life. This performance occurs at the expense of comfort and mobility, perhaps reflecting the trickle-down effect of high fashion on everyday women. Her juxtapositions of the organic with the inorganic skews relations of object and subject. The ideas of interchangeable segments of the body for decorative purposes, the prosthetized body, suggests analogies to dolls or mannequins. ${ }^{42}$ However, Laini Burton and Jana Melkumova-Reynolds note that her doll bodies often denote congruencies with her own, rupturing structural associations of the standardized body. ${ }^{43}$ Furthermore, while Katayama herself may lie in a prostrate, decorative form, her dolls often accompany her like companions, such as in her quiet series thus I exist. ${ }^{44}$ These prone, passive poses perhaps reflect gendered impositions of expected behaviour, particularly submissiveness, and also tie into Western views of Orientalism, particularly towards East Asian women. Her works comment on the stereotypical trope of the "China Doll," which both infantilizes and hypersexualizes representations of East 


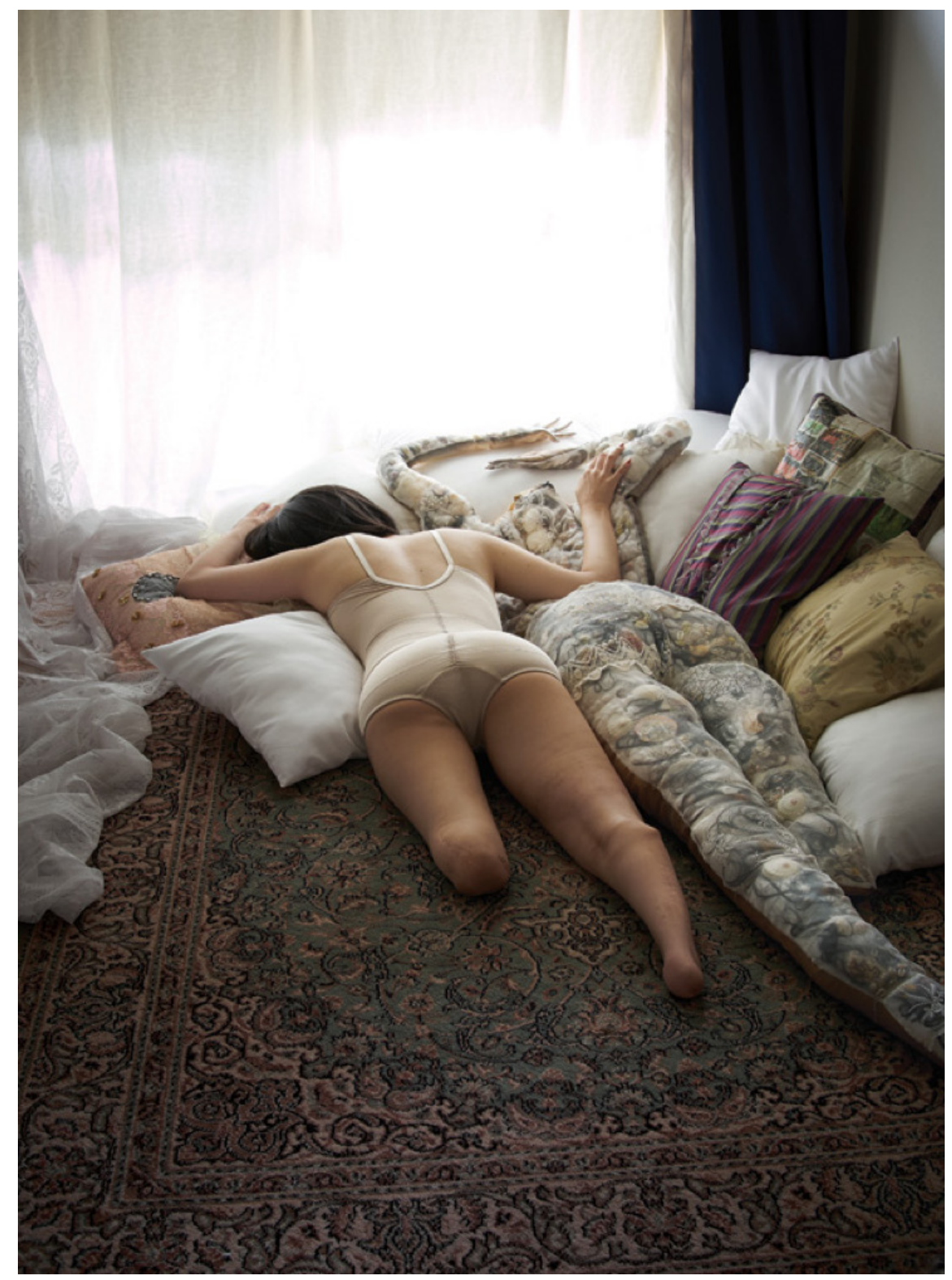

Mari Katayama, thus I exist \#2, 2015, Lambda print (credit: Mari Katayama).

Asian women. ${ }^{45}$ Katayama both fulfills and subverts the China Doll's tropes of diminutive obedience and desire to serve through her countenance of the body in non-sexualized portrayals such as thus I exist \#2, further underscored through the title. Katayama's works can best be tied together through her continual embracing of seemingly oppositional positionalities-the beautiful and grotesque, the China Doll and the disabled body.

Each of Mari Katayama's works are both visually and narratively rich. Her works are playful and demanding, combining overlapping modalities such as desire and rejection and disability and sexuality to create liminal works of art. Each work builds on the next, creating webs of visual references. I regret the shadow puppet series could not be included within this essay, especially due to its deep interplay with bystander and stunning visuals. Katayama's works allude to new futuristic worlds of the feminine and constantly ask the viewer to reposition themselves in relation to normative social standards. 


\section{Endnotes}

$1 \quad J u n k o$ Ogura and Andrea Lo, "Sewn Limbs and Surreal Backdrops in the Art of Mari Katayama," CNN, March 3, 2020, https://edition.cnn.com/style/article/mari-katayama-self-portrait/index.html.

2 Anna Battista, "No Broken Bodies, Just Beautiful Bodies: Mari Katayama @ the 58th International Art Exhibition, Venice," Irenebrination: Notes on Architecture, Art, Fashion, Fashion Law \& Technology, 2019, https://www.irenebrination.com/irenebrination_notes_on_a/2019/06/mari-katayama-venice-biennale.html.

3 Grzegorz Kubiński, "Dolls and Octopuses: The (In)human Sexuality of Mari Katayama." The Polish Journal of Aesthetics 55, no. 4, (2019): 64.

4 Mami Iida, “Mari Katayama 'Broken Heart' Talk Session with Simon Baker," RealTokyo, March 1, 2019, https://www.realtokyo.co.jp/en/interview/mari-katayamabroken-heart-white-rainbow-2019-1-24-3-2/.

5 Junko Ogura and Andrea Lo, "Sewn Limbs and Surreal Backdrops in the Art of Mari Katayama."

6 Jessica Heron-Langton, "How One Artist Used Photography to Come to Terms with Her Disability," DazedDigital,November14,2018,http:/www.dazeddigital.com/beauty/body/article/42153/1/marikatayamaphotography-disability.

7 Mari Katayama, “Atelier Shell Kashime," accessed April 4, 2021, http://shell-kashime.com.

8 Mami Iida, "Mari Katayama 'Broken Heart' Talk Session with Simon Baker."

9 Chris Campion, "Punk Prosthetics: The Mesmerising Art of Living Sculpture Mari Katayama," The Guardian, March 6, 2017, sec. Art and design, https://www.theguardian.com/artanddesign/2017/mar/06/ mari-katayama-japanese-artist-disabilities-interview.

10 Chris Campion, "The Strange Fairytales of Mari Katayama - in Pictures," The Guardian, March 6, 2017, sec. Art and Design, https://www.theguardian.com/artanddesign/gallery/2017/mar/06/haunting-photographsmari-katayama-tibial-hemimelia-japanese-artist.

11 Kubiński, "Dolls and Octopuses." 65-66. "The difference between disability and monstrosity is revealed at the meeting point, the point of friction, between a breach of the natural law-table and the breach of the law instituted by God or by society, at the point where these two breaches of law come together. Disability may well be something that upsets the natural order, but disability is not monstrosity because it has a place in civil or canon law. The disabled person may not conform to nature, but the law in some way provides for him. Monstrosity, however, is the kind of natural irregularity that calls law into question and disables it."

12 Cheung et al. "Young \& Emerging: New Bodies and Biologies." ArtAsiaPacific, no. 109 (July 2018): 74-83.

13 Kubiński, "Dolls and Octopuses." 66.

14 Ibid, 67.

15 As someone who grew up with disabled family members, and as a professional care provider, accepting living realities, needs, and bodies as individual (and this individuality thus normal) is key to creating humanizing and respectful interactions and providing informed and consensual care.

16 Iida, "Mari Katayama 'Broken Heart' Talk Session with Simon Baker."

17 Cheung et al. "Young \& Emerging."

18 Campion, "Punk Prosthetics."

19 Katayama, "Atelier Shell Kashime."

20 Battista, "No Broken Bodies, Just Beautiful Bodies."

21 Kubiński, "Dolls and Octopuses." 72.

22 Ibid, 72-3. Hokusai famously created the Great Wave off Kanagawa.

23 Kubiński, "Dolls and Octopuses." 73.

24 Rob Shields, "Donna Haraway: Staying with the Trouble," Space and Culture, April 15, 2018, https://www. spaceandculture.com/2018/04/25/donna-haraway-staying-with-the-trouble-book-review-by-juan-guevara/.

25 Posthuman gestationality is a mode of being, not necessarily only tied to the female human, but an idea based in Luce Irigay's writing on water as both 'being' and 'becoming'.

26 Astrida Neimanis, "Introduction: Figuring Bodies of Water." Bodies of Water: Posthuman Feminist Phenomenology. Bloomsbury, 2017, 4. 
27 Daisuke Igarashi, Children of the Sea, Volume 1, United States: Paw Prints, 2009. 275-283.

You can read the chapter here: https://manganelo.com/chapter/kaijuu_no_kodomo/chapter_8

28 Kubiński, "Dolls and Octopuses." 73-4.

29 Ibid, 74.

$30 \quad$ Ibid, 76.

31 Katayama, "Atelier Shell Kashime."

32 Many of the clients I work with, especially in hospital/long-term care settings, are not provided with adequate clothing. As such, many are forced to remain in hospital gowns or re-wear the same few outfits day after day. Allowing disabled individuals to make personal choices about their clothing and providing both comfortable and aesthetically pleasing choices is a vastly overlooked element in the realm of personal care, particularly in institutions.

33 Judith Butler, "Performative Acts and Gender Constitution: An Essay in Phenomenology and Feminist Theory," Theatre Journal 40, no. 4 (1988): 519-20, https://doi.org/10.2307/3207893.

34 Chris Campion, "Punk Prosthetics."

35 Laini Burton and Jana Melkumova-Reynolds, "My Leg is a Giant Stiletto Heel: Fashioning the Prosthetised Body," Fashion Theory, 23, no 2 (2019): 198. DOI: 10.1080/1362704X.2019.1567061

36 View the video here: https://youtu.be/jA8inmHhx8c

Personal anecdote: I walked in a runway show (Fashion Art Toronto, 2015) in high fashion latex to this song.

37 Burton and Melkumova-Reynolds, "My Leg is a Giant Stiletto Heel," 199.

38 Ibid, 203.

39 Burton and Melkumova-Reynolds, "My Leg is a Giant Stiletto Heel," 207.

40 Ibid, 215.

41 Iida. "Mari Katayama 'Broken Heart' Talk Session with Simon Baker."

42 Burton and Melkumova-Reynolds, "My Leg is a Giant Stiletto Heel," 212.

43 Ibid, 213-4.

44 Ibid, 212.

45 Joey Lee, "East Asian 'China Doll' or 'Dragon Lady'?," Bridges: An Undergraduate Journal of Contemporary Connections 3, no. 1 (2018): 2. 


\section{Bibliography}

Battista, Anna. "No Broken Bodies, Just Beautiful Bodies: Mari Katayama @ The 58th International Art Exhibition, Venice." Irenebrination (blog), 2019. https://www.irenebrination.com/irenebrination notes_on_a/2019/06/mari-katayama-venice-biennale.html

Black, Holly. "Mari Katayama Celebrates the Body Beautiful." ELEPHANT, 26 Jan. 2019. elephant.art/ mari-katayama-celebrates-the-body-beautiful/.

Burton, Laini and Jana Melkumova-Reynolds. "My Leg is a Giant Stiletto Heel: Fashioning the Prosthetised Body." Fashion Theory, 23, no 2 (2019): 195218. DOI:10.1080/1362704X.2019.1567061

Butler, Judith. "Performative Acts and Gender Constitution: An Essay in Phenomenology and Feminist Theory." Theatre Journal 40, no. 4 (1988): 51931. https://doi.org/10.2307/3207893.

Campion, Chris. "Punk Prosthetics: The Mesmerising Art of Living Sculpture Mari Katayama." The Guardian, March 6, 2017, sec. Art and design. https:// www.theguardian.com/artanddesign/2017/ mar/06/mari-katayama-japanese-artist-disabilities-interview.

" "The Strange Fairytales of Mari Katayama - in Pictures," The Guardian, March 6, 2017, sec. Art and design. https://www.theguardian.com/ artanddesign/gallery $/ 2017 / \mathrm{mar} / 06 /$ hauntingphotographs-mari-katayama-tibial-hemimeliajapanese-artist

Cheung, Ysabelle, Chloe Chu, Julee Woo Jin Chung, Ophelia Lai, and H. G. Masters. "Young \& Emerging: New Bodies and Biologies." ArtAsiaPacific, no. 109 (July 2018): 74-83.

Cohen, Alina. "In Opulent Self-Portraits, Mari Katayama Rejects Standard Beauty Norms." Artsy, May 27, 2019. https://www.artsy.net/article/artsy-editorial-opulent-self-portraits-mari-katayama-rejectsstandard-beauty-norms

Heron-Langton, Jessica. "How One Artist Used Photography to Come to Terms with Her Disability." Dazed Digital, November 14, 2018. www.dazeddigital.com/beauty/body/article/42153/1/mari-katayama-photography-disability.

Igarashi, Daisuke. Children of the Sea, Volume 1. United States: Paw Prints, 2009.
Iida, Mami. "Mari Katayama 'Broken Heart' Talk Session with Simon Baker." RealTokyo, March 1, 2019. https://www.realtokyo.co.jp/en/interview/mari-katayamabroken-heart-white-rainbow-2019-1-24-3-2/.

Ito, Hitomi. "Choosing High Heels with Amputated Legs / Artist, Mari Katayama: Fragments." Fragments International, www.fragmentsmag. com/en/2012/06/interview-katayama-mari/.

Katayama, Mari. "Atelier Shell Kashime," accessed April 4, 2021, http://shell-kashime.com.

Kubiński, Grzegorz. "Dolls and Octopuses. The (In)human Sexuality of Mari Katayama." The Polish Journal of Aesthetics 55, no. 4/2019 (2019): 63-78.

Lee, Joey. "East Asian 'China Doll' or 'Dragon Lady"?" Bridges: An Undergraduate Journal of Contemporary Connections 3, no. 1 (2018): 1-6.

Neimanis, Astrida. Bodies of Water: Posthuman Feminist Phenomenology. London: Bloomsbury Academic, 2017.

Ogura, Junko, and Andrea Lo. "Sewn Limbs and Surreal Backdrops in the Art of Mari Katayama." CNN, March 3, 2020. https://edition.cnn.com/style/ article/mari-katayama-self-portrait/index.html.

Shields, Rob. "Donna Haraway: Staying with the Trouble." Space and Culture, April 15, 2018. https:// www.spaceandculture.com/2018/04/25/donnaharaway-staying-with-the-trouble-book-reviewby-juan-guevaral.

Siebers, Tobin. "A Sexual Culture of Disabled People," in Sex and Disability, ed. Robert McRuer et al. (Durham-London: Duke University Press, 2012), 7-53.

"Bridging the Gap Between 'Abnormal' and 'Normal' | Mari Katayama First Solo Exhibition 'You'Re Mine.'” Fragments International Magazine, 30 Mar. 2015, www.fragmentsmag.com/en/2015/03/mari-katayama-youre-mine/4/.

“Biennale Arte 2019: Mari Katayama." La Biennale Di Venezia, 29 May 2019, www.labiennale.org/en/ art/2019/partecipants/mari-katayama. 